\title{
Functional and radiological assessment of total ankle replacement with Infinity prosthesis
}

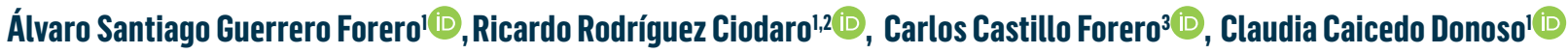 \\ 1. Hospital de San José Bogotá, Bogotá, Colombia. \\ 2. Fundación Universitaria de Ciencias de la Salud Bogotá, Bogotá, Colombia. \\ 3. Clínica de la Colina, Bogotá, Colombia.
}

\begin{abstract}
Objective: To present mid-term functional and radiological outcomes obtained with the use of Infinity prosthesis in Bogotá (Colombia). Methods: This cross-sectional observational study selected consecutive patients subjected to total ankle replacement with the fourth generation Infinity prosthesis (Wright Medical Technology).

Results: Fifty-two patients with ankle arthrosis were followed for a mean period of 24 months, and the most frequently reported case of joint degeneration was trauma. Postoperative improvement was observed in perception of pain (visual analog scale increased from $8 / 10$ to 2/10; $p<0.0005$ ), AOFAS functional scale (from 23 to 84.5; $\mathrm{p}<0.0005$ ), and range of motion (from $11^{\circ}$ to $29^{\circ} ; \mathrm{p}<0.0005$ ). Similarly, radiological findings, implant positioning, and signs of loosening did not reveal implant failure.

Conclusions: The use of fluoroscopically navigated prostheses allows us to achieve predictable outcomes, with satisfactory mid-term clinical and imaging results.
\end{abstract}

Level of Evidence IV; Therapeutic Studies; Case Series.

Keywords: Arthrosis; Ankle; Joint prosthesis; Arthroplasty, replacement, ankle.

\section{Introduction}

For patients, end-stage tibiotalar joint arthrosis represents limited limb function and thus limitations in performing everyday activities (Figure 1). Ankle arthrodesis has been widely indicated as a therapeutic option that promotes pain control and allows for gait of enough quality for the performance of basic everyday tasks ${ }^{(1,2)}$. However, restricted tibiotalar range of motion generates overload on transtarsal and tarsometatarsal joints, which, in the mid and long term, leads to arthrosis of these joints (50\% of patients present with changes related to hindfoot arthrosis the 8 years after disease onset, but at 20 years, all patients had developed joint degeneration) $)^{(3-8)}$.

Therefore, in the last decade total ankle arthroplasty, associated with biomedical advances in implants, has become a technique to solve limitation secondary to end-stage ankle arthrosis ${ }^{(9,10)}$, with the advantage of not restricting mobility and preventing the transfer of load to neighboring joints.
Total ankle arthroplasty has shown promising results in the current literature, in terms of durability and function; therefore, it is considered by many authors the gold standard for the treatment of end-stage tibiotalar arthrosis ${ }^{(11)}$.

The aim of this study is to present the results obtained with the use of Infinity prosthesis over the last 4 years.

\section{Methods}

According to resolution 8430 of 1993 of the Ministry of Protection, the present study is considered an investigation that does not pose significant risks to patients (Resolution 8430 of 1993 of the Ministry of Health of the Republic of Colombia, Article 10 and 11), because it consisted of a review of information collected from a database of patients subjected to ankle joint replacement. Ethical guidelines were based on the Declaration of Helsinki as revised in 2013, especially on articles 22, which refers to the development of a research protocol, and article 24 , which ensures the confidentiality of data from study participants.
Study performed at the Hospital de San José - Fundación de Ciencias de la Salud, Bogotá, Colombia.

Correspondence: Álvaro Santiago Guerrero Forero. Calle 10 № 18-75, 111711 Bogatá, Colombia. E-mail: satiagoguerrero@hotmail.com. Conflicts of Interest: Consultor Wright Medical Tecnology. Source of funding: none. Date received: July 26, 2021. Date accepted: July 30, 2021. Online: August 31, 2021.
How to cite this article: Guerrero Forero AS, Rodríguez Ciodaro R, Castillo Forero C, Caicedo Donoso $C$. Functional and radiological assessment of total ankle replacement with Infinity prosthesis. J Foot Ankle. 2021;15(2):105-9. 

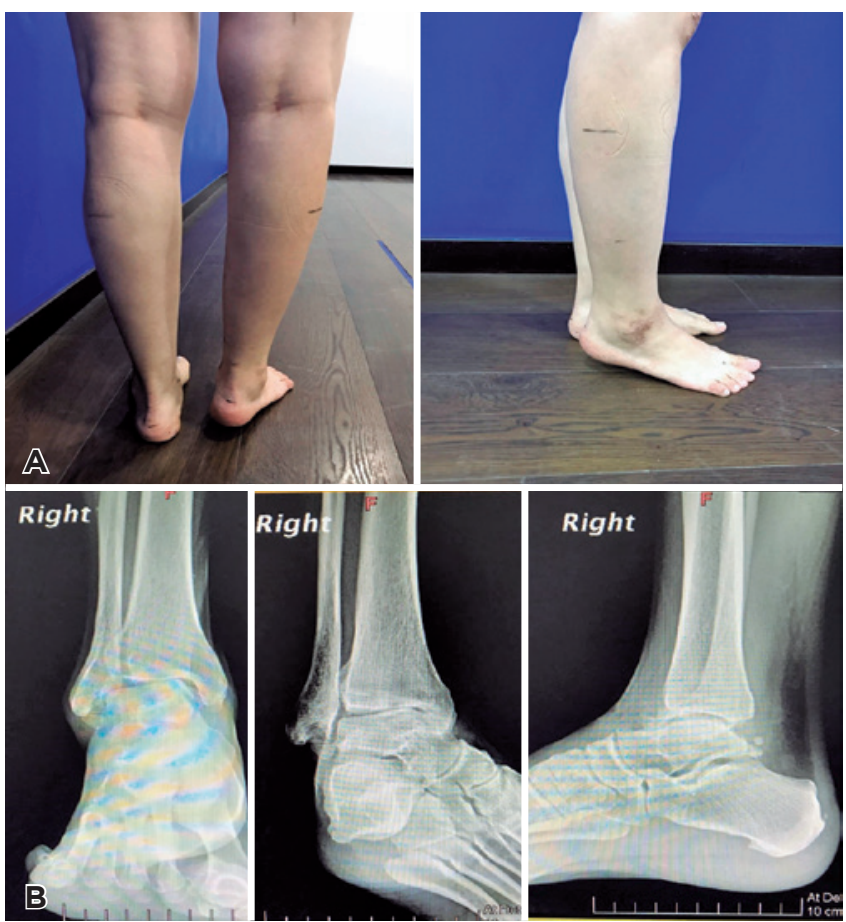

Figure 1. Thirty-six-year-old patient with history of ankle fracture. A) Clinical photos showing equinus deformity of $12^{\circ}$. B) X-ray of the right ankle with support.

Since the present investigation is a study without significant risks, the Research Ethics Committee of the research institution waived the requirement of obtaining written informed consent (Resolution 8430 of 1993 Ministry of Health of the Republic of Colombia - First Paragraph).

This is a cross-sectional observational study that selected consecutive patients subjected to total ankle replacement with fourth generation Infinity prosthesis, performed by the foot and ankle surgery team.

Pre- and immediate, four-week, six-month, and one-year postoperative radiographic images, obtained in the anteroposterior and lateral planes, were assessed through radiographic measurements according to the parameters described by Hintermann et al. ${ }^{(12-14)}$ to evaluate misalignment and signs of wearing or loosening of prosthesis components (Figure 2):

- Malalignment: corresponds to measures that were not within the established ranges for $\alpha, \beta$, and $\theta$ angles;

- $\alpha$ angle: angle between the anatomical axis of the tibia and the joint surface of the tibial component of the prosthesis, in the coronal view, with a normal value of $90^{\circ}$ (normal range [NR] 86-92);

- $\beta$ angle: angle between the anatomical axis of the tibia and the joint surface of the tibial component of the prosthesis, in sagittal view, with a normal angle of $85^{\circ}$ (NR 82-88);
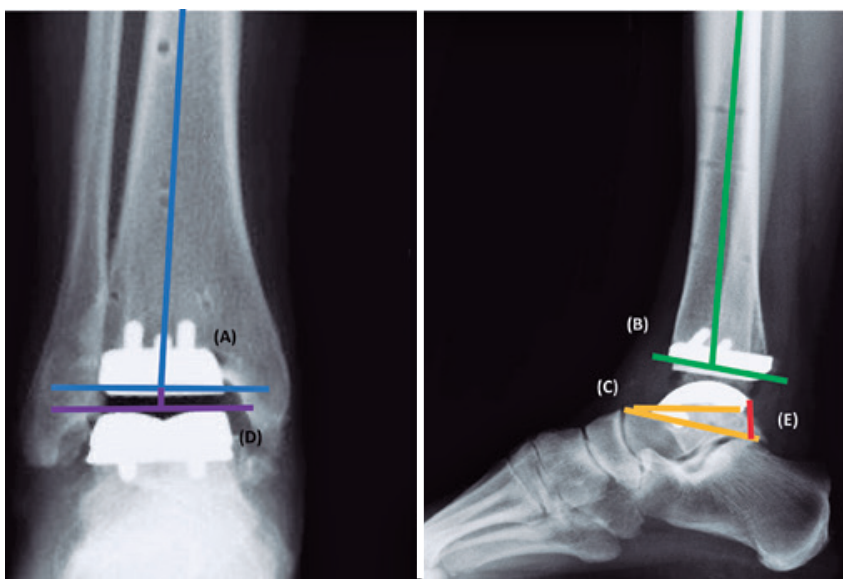

Figure 2. Radiographic parameters for the assessment of Infinity prosthesis (Wright Medical Technology) alignment. A) $\alpha$ angle in blue. B) $\beta$ angle in green. C) $\theta$ angle in orange. D) Tibiotalar angle in purple. E) Distance "b" in red.

- $\Theta$ angle: angle composed of the union of the line going through the anterior and posterior extremities of the talar component of the prosthesis (line A) and the line tangential to the upper edge of the navicular and the upper eminence of the posterior tuberosity of the calcaneus (line B), with a normal value of $20^{\circ}$;

- Tibiotalar angle: angle between the axis of the tibia and a line perpendicular to the talar dome. Negative values represent varus angulations, whereas positive ones represent valgus angulations.

- Distance "a": distance between the anterior extremity of the talar component of the prosthesis and line A, measured in millimeters;

- Distance "b": distance between the posterior extremity of the talar component of the prosthesis and line B, measured in millimeters.

\section{Statistical analysis}

This is a cross-sectional observational study that selected consecutive patients subjected to total ankle replacement with fourth generation Infinity prosthesis (Wright Medical Technology).

Data were collected on an Excel spreadsheet and then exported to the Stata ${ }^{\circledR}$ Software, version 14 , for further analysis. Qualitative variables were reported using measures of absolute and relative frequency, and quantitative variables were reported using measures of central trend and dispersion, depending on data distribution: data with normal distribution are expressed as mean and standard deviation, whereas those with non-normal distribution are expressed as median and interquartile range (IQR). 


\section{Results}

The present study evaluated the clinical-radiographic outcomes of patients subjected to total ankle replacement with Infinity prosthesis (Wright Medical Technology) due to end-stage arthrosis. Mean follow-up time was 24 months (9.5-55 months); mean age was 61 years (53-67 years). With regard to the operated side, $53.8 \%$ of interventions were performed on the right ankle, and $46.2 \%$ on the left ankle. The cause of arthrosis was post-traumatic in $61.9 \%$ of the cases, whereas $38.1 \%$ of the cases had another origin (rheumatoid arthritis, gout, and hemophilia) (Tables 1 and 2).

Table 1. Demographic data

\begin{tabular}{|c|c|c|}
\hline \multicolumn{3}{|c|}{ Demographic data } \\
\hline \multicolumn{3}{|c|}{ Variables } \\
\hline Age, mean & & 61 \\
\hline \multirow[t]{2}{*}{ Gender } & Male & $51 \%$ \\
\hline & Female & $49 \%$ \\
\hline \multirow[t]{2}{*}{ Race } & White & $98 \%$ \\
\hline & Non-white & $1 \%$ \\
\hline
\end{tabular}

Table 2. Distribution of cause and radiological findings

\begin{tabular}{|c|c|c|}
\hline \multicolumn{3}{|c|}{ Characteristics of the prosthesis } \\
\hline \multicolumn{3}{|c|}{ Variables } \\
\hline \multirow[t]{2}{*}{ Operated side } & Right & $53.84 \%$ \\
\hline & Left & $46.36 \%$ \\
\hline \multirow[t]{2}{*}{ Cause } & Degenerative & $38.10 \%$ \\
\hline & Post-traumatic & $61.40 \%$ \\
\hline Periprosthetic cyst & & $0 \%$ \\
\hline Talar subsidence & & $0 \%$ \\
\hline $\begin{array}{l}\text { Polyethylene } \\
\text { wearing }\end{array}$ & & $0 \%$ \\
\hline \multirow[t]{5}{*}{ Associated surgery } & None & $80 \%$ \\
\hline & Achilles tendon lengthening & $9.62 \%$ \\
\hline & Subtalar arthrodesis & $1.92 \%$ \\
\hline & Syndesmosis fixation & $1.92 \%$ \\
\hline & Calcaneal osteotomy & $5.77 \%$ \\
\hline \multirow[t]{3}{*}{ Malleolus fracture } & None & $96.10 \%$ \\
\hline & Lateral & $1.92 \%$ \\
\hline & Medial & $1.92 \%$ \\
\hline \multirow{5}{*}{$\begin{array}{l}\text { Wound } \\
\text { complications }\end{array}$} & No complications & $92.31 \%$ \\
\hline & Necrosis of wound extremities & $7.69 \%$ \\
\hline & Extensive necrosis (implant) & $0 \%$ \\
\hline & Extensive necrosis (vascularized flap) & O\% \\
\hline & Infection & O\% \\
\hline Prosthesis failure & & $\mathrm{O} \%$ \\
\hline Salvage & & $0 \%$ \\
\hline
\end{tabular}

A visual analog scale was used to assess pre- and postoperative pain, with a mean preoperative score of $8 / 10$ (5-10) and a mean postoperative score of $2 / 10(0-3)$, showing a statistically significant improvement $(p<0.0005)$ (Table 3$)$.

All patients were evaluated with the American Orthopaedic Foot and Ankle Society (AOFAS) for the ankle, with a mean preoperative score of 23 points (20-30.5), and a mean postoperative score of 84.5 points ( $80-90)$, showing a statistically significant improvement $(\mathrm{p}<0.0005)$.

Actual ankle range of motion, interpreted as the sweep angle from maximum active extension to maximum active flexion, had mean preoperative and postoperative values of 11 degrees (5-30) and 29 degrees (20-40), respectively, representing a statistically significant difference $(p<0.0005)$.

Our study assessed the postoperative radiographic outcomes of patients subjected to total ankle replacement due to end-stage arthrosis. Control images were obtained at the postoperative immediate period and at three, six, and twelve postoperative months, in anteroposterior, lateral, and mortise views.

During follow-up, there were no signs of early loosening (periprosthetic radiolucent lines) or variation in angle measures suggesting subsidence of prosthetic components or polyethylene implant wearing.

Furthermore, the indication of procedures in parallel with arthroplasty was assessed; $80 \%$ of the cases did not require an associated surgical intervention. The most frequently indicated procedure was Achilles tendon lengthening, followed by calcaneal osteotomy. During follow-up, no patient required revision surgery.

\section{Discussion}

Infinity ankle prosthesis (Wright Medical Technology) is a fourth-generation implant characterized by low profile, fluo-

Table 3. Pre- and postoperative findings

\begin{tabular}{|c|c|c|c|c|}
\hline Variable & Median & Minimum & Maximum & $\begin{array}{l}\text { Interquartile } \\
\text { range }\end{array}$ \\
\hline Preoperative VAS & 8 & 5 & 10 & 7 to 9 \\
\hline Postoperative VAS & 2 & 0 & 3 & 1 to 2 \\
\hline $\begin{array}{l}\text { Preoperative } \\
\text { AOFAS score }\end{array}$ & 23 & 13 & 40 & 20 to 30.5 \\
\hline $\begin{array}{l}\text { Postoperative } \\
\text { AOFAS score }\end{array}$ & 84.5 & 80 & 92 & 80 to 90 \\
\hline Preoperative ROM & 10 & 5 & 30 & 7.5 to 15 \\
\hline $\begin{array}{l}\text { Postoperative } \\
\text { ROM }\end{array}$ & 28 & 20 & 40 & 25 to 30 \\
\hline $\begin{array}{l}\text { Real preoperative } \\
\text { mobility }\end{array}$ & 1 & 0 & 3 & 1 \\
\hline $\begin{array}{l}\text { Real postoperative } \\
\text { mobility }\end{array}$ & 30 & 20 & 40 & 30 \\
\hline Distance “a” & 2 & 1 & 5 & 2 \\
\hline Distance "b" & 4 & 2 & 6 & 4 to 5 \\
\hline
\end{tabular}

AOFAS= American Orthopaedic Foot and Ankle Society; ROM= range of motion; VAS= visual analog scale 
roscopically navigated, fixed-bearing device with a symmetrical condylar geometry that uses a resurfacing and fluoroscopic navigation system ${ }^{(15,16)}$. Since its use was initiated in 2013, this prosthesis has demonstrated satisfactory clinical and radiological outcomes. In Colombia, its use has increased since 2016, with favorable results, being even more used than arthrodesis as the therapeutic method in end-stage ankle arthrosis.

The rates of complications and revision of ankle prosthesis were considerably high compared to those observed in knee and hip arthroplasties, which has changed with the development of new generations of implants, in which fixation with tibial/talar pegs and resurfacing have reduced the effect of shear stress on implant components ${ }^{(16)}$.

Cody et al. ${ }^{(17)}$, Althoff et al. ${ }^{(18)}$, and DeVries et al. ${ }^{(19)}$ reported a rate of revision of $10 \%$, whose more frequent causes were loosening of prosthetic components (3.8\%) and deep infection (3.8\%) in 159 ankles in a 20-month follow-up. However, in the same year, Penner et al. ${ }^{(9)}$ published their two-year follow-up with Infinity prosthesis in 67 patients requiring total ankle arthroplasty. In this cohort, $3 \%$ of participants required prosthetic revision for aseptic loosening. Similarly, there was a significant improvement in the Foot Function Index and Ankle Osteoarthritis Scale functional scores $(p<0.0001)$.

Rushing et al. (20), in turn, assessed 55 ankles over a follow-up time of up to 43 months, with a rate of prosthesis survivorship of $97 \%$ and a rate of revision $1.8 \%$; moreover, radiolucency was observed in $34.5 \%$ of the ankles, of which $89.5 \%$ were not progressive. Improvement of angle deformity was achieved both in the coronal and sagittal planes $(p<0.001$ and $p<0.09$, respectively).

Saito et al. ${ }^{(16)}$ reports a rate of revision surgery of $4.7 \%$ in a 25-month follow-up of a cohort of 64 patients (18), similar to the rates observed with other implants. Meanwhile, the United Kingdom National Joint Register found that only $1 \%$ of cases required revision of Infinity prosthesis in a 14-month follow-up ${ }^{(9,16-20)}$.

In Latin America, a 2020 study by Nery et al.(3) reported successful outcomes in 26 patients subjected to arthroplasty with Infinity prosthesis, with a $100 \%$ rate of survivorship in the first year of follow-up, which is similar to the result found in our study, although the present study had a larger sample size and longer follow-up.

Prostheses with fluoroscopic navigation (Figure 3) enhance the accuracy of postoperative outcomes with regard to implant alignment; in 2018 King et al.(15) found, in a cohort of 20 patients with a 24 -month follow-up, a deviation of $1.5^{\circ}$ from $90^{\circ}$ alignment to the anatomical axis of the tibia, which allows for a homogeneous distribution of body load that is translated in the preservation of implant components. Similarly, Saito et al. ${ }^{(16)}$ reported improvement in tibiotalar coronal alignment with the use of a fluoroscopically navigated prosthesis, as shown by the maintenance of the prosthesis and consistent with the results observed in our radiological follow-up assessment.

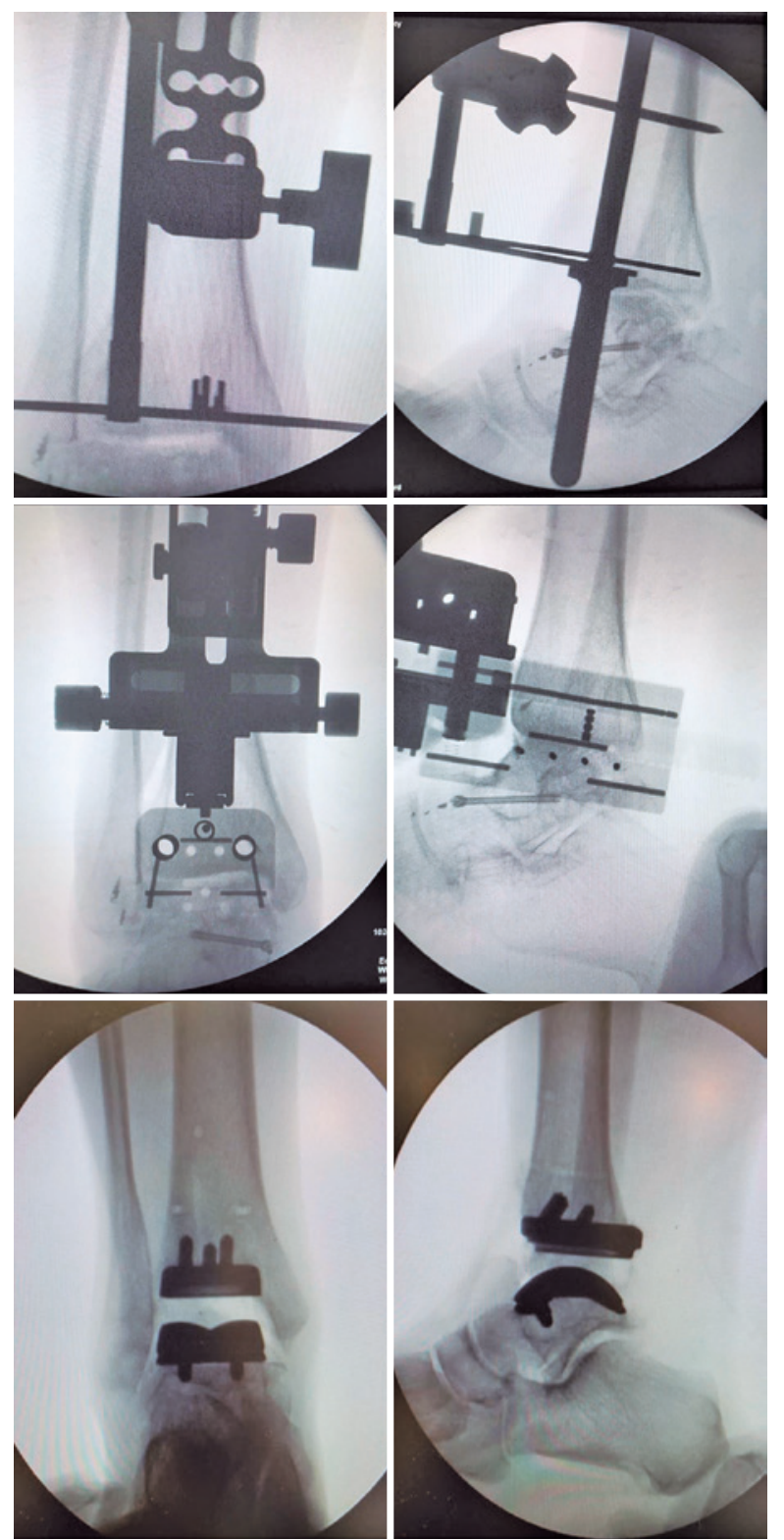

Figure 3. Fluoroscopic sequence of total ankle replacement with Infinity prosthesis (Wright Medical Technology).

General complications related to the use of this prosthesis are reported in up to $54 \%$ of the cases $^{(15,16)}$ and, in the cohort by Saito et al. ${ }^{(16)}$, consisted mainly of impingement of the lateral groove. However, the most frequent complication in our sample was that involving soft tissues.

\section{Conclusion}

Total ankle replacement with Infinity prosthesis allows for a reproducible technique with satisfactory mid-term clinical and radiological outcomes. Thus, we consider that results for long-term prognosis are promising, but a longer patients' follow-up is required. 
Authors' contributions: Each author contributed individually and significantly to the development of this article: ASGF *(https://orcid.org/OOOO-OOO30296-5263) Conceived and planned the activities that led to the study, participated in the review process, performed the surgeries, data collection, survey of the medical records, formatting of the article, clinical examination, approved the final version; RRC *(https://orcid.org/O000-002-3817-0609) Conceived and planned the activities that led to the study, participated in the review process, performed the surgeries, data collection, survey of the medical records, formatting of the article, clinical examination, approved the final version; CCF *(https://orcid.org/0000-0002-5197-4468) Performed the surgeries, data collection, survey of the medical records; CCD *( https://orcid.org/0000-0002-8049-3903) Interpreted the results of the study, participated in the review process, statistical analysis, bibliographic review, formatting of the article, clinical examination, approved the final version. All authors read and approved the final manuscript. *ORCID (Open Researcher and Contributor ID) (iD).

\section{References}

1. Escudero MI, Le V, Barahona M, Symes M, Wing K, Younger A, et al. Total Ankle Arthroplasty Survival and Risk Factors for Failure. Foot Ankle Int. 2019;40(9):997-1006.

2. Daniels TR, Younger AS, Penner M, Wing K, Dryden PJ, Wong H, et al. Intermediate-term results of total ankle replacement and ankle arthrodesis: a COFAS multicenter study. J Bone Joint Surg Am. 2014;96(2):135-42.

3. Nery C, Lemos AVKC, Ferreira Martins CEC, Baumfeld D. Brazilian Total Ankle Replacement Experience. Orthop Clin North Am. 2020; 51(2):293-302.

4. Wang H, Brown SR. The effects of total ankle replacement on ankle joint mechanics during walking. J Sport Health Sci. 2017;6(3):340-5.

5. Latham WC, Lau JT. Total Ankle Arthroplasty: An Overview of the Canadian Experience. Foot Ankle Clin. 2016;21(2):267-81.

6. Barg A, Wimmer MD, Wiewiorski M, Wirtz DC, Pagenstert GI, Valderrabano V. Total ankle replacement. Dtsch Arztebl Int. 2015; 112(11):177-84

7. Besse JL, Colombier JA, Asencio J, Bonnin M, Gaudot F, Jarde O, et al. Total ankle arthroplasty in France. Orthop Traumatol Surg Res. 2010;96(3):291-303.

8. Prusinowska A, Krogulec Z, Turski P, Przepiórski E, Małdyk P, Księżopolska-Orłowska K. Total ankle replacement - surgical treatment and rehabilitation. Reumatologia. 2015;53(1):34-9.

9. Penner M, Davis WH, Wing K, Bemenderfer T, Waly F, Anderson RB. The Infinity Total Ankle System: Early Clinical Results With 2to 4-Year Follow-up. Foot Ankle Spec. 2019;12(2):159-66.

10. Younger AS, Wing KJ, Glazebrook M, Daniels TR, Dryden PJ, Lalonde KA, et al. Patient expectation and satisfaction as measures of operative outcome in end-stage ankle arthritis: a prospective cohort study of total ankle replacement versus ankle fusion. Foot Ankle Int. 2015;36(2):123-34
11. Nery C, Fernandes TD, Réssio C, Fuchs ML, Santos ALG, Ortiz RT. Total Ankle Replacement: Brazilian Experience with the HINTEGRA Prosthesis. Rev Bras Ortop. 2010;45(1):92-100.

12. Hintermann B, Valderrabano V, Dereymaeker G, Dick W. The HINTEGRA ankle: rationale and short-term results of 122 consecutive ankles. Clin Orthop Relat Res. 2004;(424):57-68.

13. Hintermann B. Surgical techniques. In: Total ankle arthroplasty: historical overview, current concepts and futures perspectives. 5th ed. New York: Springer-Verlang; 2005. p. 115-31.

14. Hintermann B, Valderrabano V, Knupp M, Horisberger M. [The HINTEGRA ankle: short- and mid-term results]. Orthopade. 2006; 35(5):533-45

15. King A, Bali N, Kassam AA, Hughes A, Talbot N, Sharpe I. Early outcomes and radiographic alignment of the Infinity total ankle replacement with a minimum of two year follow-up data. Foot Ankle Surg. 2019;25(6):826-33.

16. Saito GH, Sanders AE, de Cesar Netto C, O'Malley MJ, Ellis SJ, Demetracopoulos CA. Short-Term Complications, Reoperations, and Radiographic Outcomes of a New Fixed-Bearing Total Ankle Arthroplasty. Foot Ankle Int. 2018;39(7):787-94.

17. Cody EA, Taylor MA, Nunley JA 2nd, Parekh SG, DeOrio JK. Increased Early Revision Rate With the INFINITY Total Ankle Prosthesis. Foot Ankle Int. 2019;40(1):9-17.

18. Althoff A, Cancienne JM, Cooper MT, Werner BC. Patient-Related Risk Factors for Periprosthetic Ankle Joint Infection: An Analysis of 6977 Total Ankle Arthroplasties. J Foot Ankle Surg. 2018;57(2):269-72.

19. DeVries JG, Derksen TA, Scharer BM, Limoni R. Perioperative Complications and Initial Alignment of Lateral Approach Total Ankle Arthroplasty. J Foot Ankle Surg. 2017;56(5):996-1000.

20. Rushing CJ, Kibbler K, Hyer CF, Berlet GC. The INFINITY Total Ankle Prosthesis: Outcomes at Short-Term Follow-up. Foot Ankle Spec. 2020:1938640020946199. 